\title{
Research Paper: \\ Post-Market Surveillance Study of a Skull Flap Fixation Device: Cranfixer
}

\author{
Seyed Roholah Ghodsi ${ }^{1^{*}}$, Hosein Esmaili Dezaki ${ }^{1}$, Morteza Alizadeh ${ }^{2}$, Zahra Namazi ${ }^{3}$ \\ 1. DanaWell Company, Tehran University of Medical Sciences, Tehran, Iran \\ 2. Department of Tissue Engineering, School of Advanced Technologies, Shahrekord University of Medical Sciences, Shahrekord, Iran \\ 3. Department of Dental Biomaterials, School of Dentistry, Shahid Beheshti Univeristy of Medical Sciences, Tehran, Iran
}

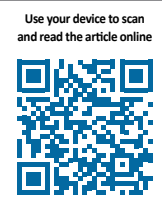

Citation Ghodsi SR, Esmaili Dezaki H, Alizadeh M, Namazi Z. Post-Market Surveillance Study of a Skull Flap Fixation Device: Cranfixer Iran J Neurosurg. 2019; 5(2):55-62. http://dx.doi.org/10.32598/irjns.5.2.55

http://dx.doi.org/10.32598/irjns.5.2.55

Article info:

Received: 10 Jan 2019

Accepted: 05 Mar 2019

Available Online: 01 April 2019

Keywords:

Internal fixators, Skull, Burr hole cover, Cranfixer, Product surveillance, Postmarketing

\section{ABSTRACT}

Background and Aim: Cranfixer was approved in 2017 by the Food and Drug Administration of Iran as a skull flap fixation and also a burr hole cover. The effectiveness and safety of this commercial medical device were investigated in detail by the regulatory auditors.

Methods and Materials/Patients: Cranfixer was used for ninety-five patients. Sixty patients were selected from a list if they had at least two follow-ups after surgery. The following variables were investigated: age, gender, number of Cranfixers, device loosening, infection, and prominence. In addition, a retrospective review was performed about the reason of surgery.

Results: Flap loosening and infection were the major variables surveyed. On average, two Cranfixers were used for each patient. Patients' median age was 44 years. There was no sex preference (50\% male). The craniotomy occurred in frontal (50\%), occipital (3\%), parietal ( $20 \%)$, and temporal $(27 \%)$ lobes. Based on examination and CT imaging, no cases of loosening were observed. Just in one patient, one of two Cranfixers was infected $(\mathrm{P}<0.001)$.

Conclusion: The reliability and functionality of Cranfixer were proved in pre-market test and the results of this study confirm them. Cranfixer provides safe, reliable and long-term functionality.

* Corresponding Author:

Seyed Roholah Ghodsi, PhD.

Address: DanaWell Company, Tehran University of Medical Sciences, Tehran, Iran

Tel: +98 (21) 83384167

E-mail: roholahghodsi@gmail.com 


\section{Highlights}

- The reliability and functionality of Cranfixer is studied based on the clinical data.

- Cranfixer provides safe, reliable and long-term functionality.

- The thickness of Cranfixer should be revised without loss of strength and product performance.

\section{Plain Language Summary}

The cranfixer is a medical device in neurosurgery field manufactured by Darman Afarin Noandish Afagh co (DanaWell). The most remarkable outcome of this study is the functionality of Cranfixer. Cranfixer is a skull flap fixation and also a burr hole cover. The clinical investigation lasted up to 18 months. This device was approved in 2017 by the Food and Drug Administration of Iran.

\section{Introduction}

raniotomy is a common surgical procedure in neurosurgery. After craniotomy, the removed piece of bone must be returned. Various fixation techniques are used for securing the bone in place. These techniques vary from making holes in the bone and simple suturing to fixation with the biocompatible implantable fixators.

Suturing technique is a basic method in which a stainless steel wire is used to secure the fixation [1]. Holes are drilled in the flap and the adjacent bone which are twisted with a wire that passes through the holes. In addition, the strips are used to fix skull flaps in place with screws [2].

The most novel technique is clamping the flap. The clamping method is simple to use and reduces the surgery time. Clamps are made of different materials such as titanium and PEEK $[3,4]$. Cranfixer is made of Poly-
Methyl Methacrylate (PMMA), a well-known long-term biocompatible material that has long been used $[5,6]$. Cranfixer was approved by Iran's Ministry of Health and Medical Education after qualification review and related standard audition for biocompatibility, mechanical strength, and easy handling. We examined and reported surgeon experience and patient satisfaction in the present study. Cranfixer is fixed with silk sutures as shown in Figure 1. This is an easy and applicable mechanism. In Figure 2, a flap fixation is shown with two Cranfixers.

\section{Methods and Materials/Patients}

Sixty patients who had at least two follow-ups were included in this study. The main cause of surgery was brain tumors. Patients' age ranged from 14 to 82 years (mean age=44). There were equal numbers of male and female. Cranfixer was used in different parts of the skull as shown in Figure 3.

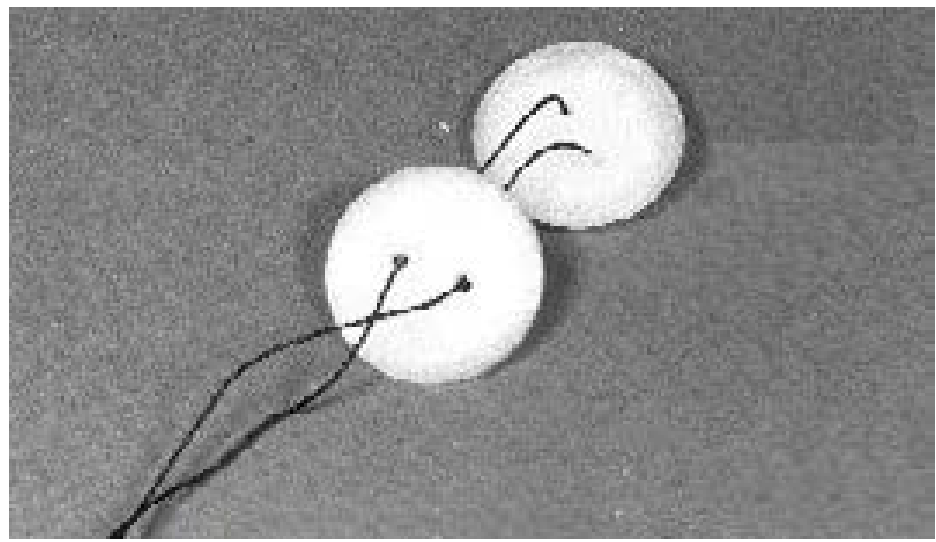

Figure 1. Cranfixer 


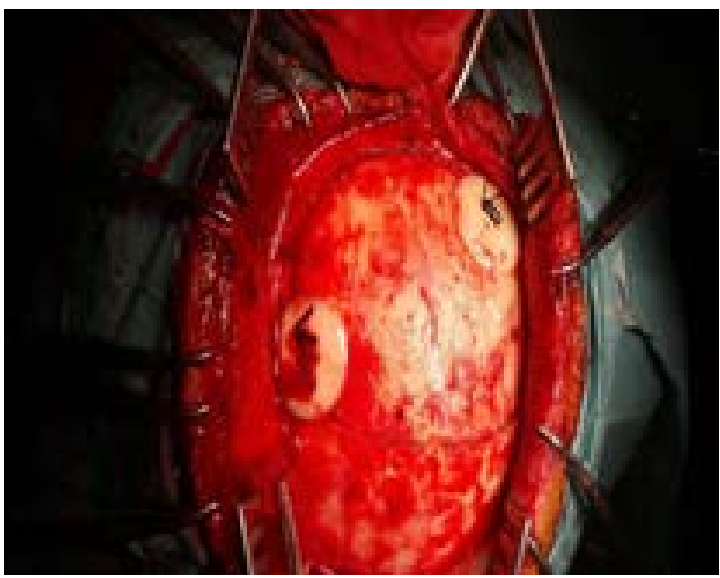

Figure 2. Flap fixation with Cranfixer

Different measures were chosen to evaluate infection, device loosening and prominence through scalp (both visual and touch) from surgeons' and patients' perspective. Follow-ups ranged from 143 to 523 days with a mean follow-up of 342 days. Pearson's chi-square method was used for statistical analysis.

Characteristics and demographics of the participants were summarized with descriptive statistics. Patients were referred for therapy and selected from the age range of 14 to 82 years old, consisting of males and females. It was not possible to blind the surgeons because they were familiar with Cranfixer. Clinical Research Form/Case Report Form (CRF) was developed according to the guidelines of FDA of Iran and CONSORT statement.

The first part of this study obtained data from the surgeon's experience at the time of surgery. The second part of data was collected from patient follow-ups in two rounds. Comorbidities like immunodeficiency were not observed in these follow-ups.

Cranfixers were used in frontal, temporal, parietal and occipital regions of the skull. Complications such as in- fection, loosening, visual prominence and tactile prominence were included in statistical analysis. According to the surgical history, patients were followed up 143 to 523 days to assess the instances listed. Pearson's chisquare was used for statistical analysis.

In accordance with the ethical principles and the national norms and standards for conducting medical research in Iran, the questionnaire and method of this study were evaluated and approved by the Research Deputy of Tehran University of Medical Sciences (IR. TUMS.VCR.REC.1397.657)

\section{Results}

As mentioned before, patients with at least two followups are reported in this study. Figure 4 shows the implanted Cranfixers in some postoperative images.

Table 1 presents patient demographics: gender, age, follow-up duration, number of Cranfixers used, size of bone flap, location of bone flap in the skull, patient's disease, flap loosening, infection and prominence (visual/ tactile). In the following, the variables and the data are presented in tables and charts. The variables are: 1 ) gen-

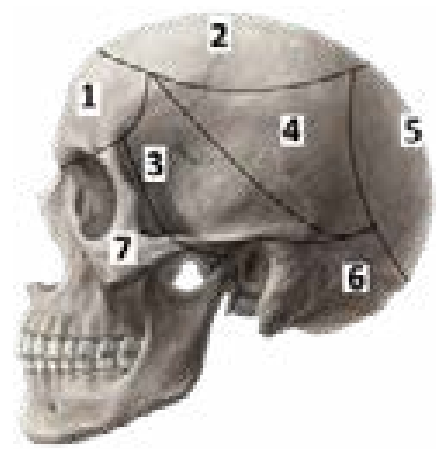

Figure 3. skull segmentation 


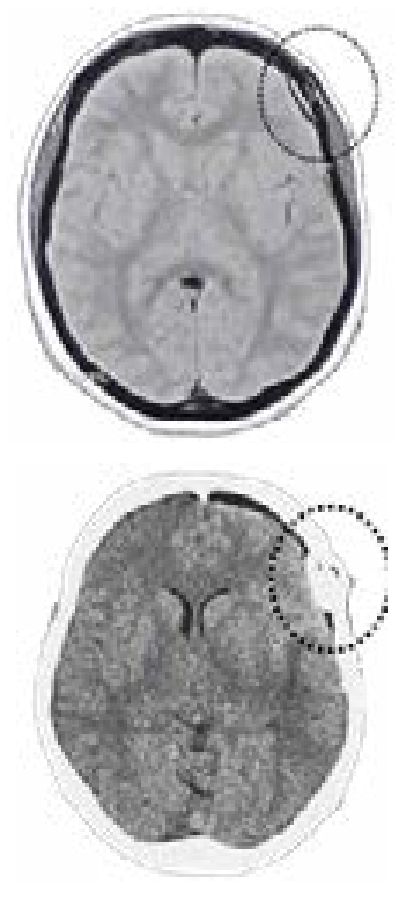

Figure 4. Cranfixers in postoperative images of different patients

der, 2) age, 3) duration of the follow-up, 4) number of Cranfixers used for each patient, 5) flap size, 6) location of defect on the skull, 7) disease, 8) flap loosening, 9) infection, and 10) prominence (visual/tactile) (Table 1). The quantitative variables are described in Table 2 . The mean age of patients was 44 years old (ranged: 14-82).

Another important quantitative variable is the followup duration. Among 95 patients, 60 individuals were selected with at least two follow-ups. The mean follow-up duration was 342 days while the longest duration of 525 days belonged to a 14-year-old girl. In most surgeries, two Cranfixers were used for each patient. Totally, 118 Cranfixers were implanted in 60 patients.

Table 3 presents some variables about the surgery. Most of the dissection flaps were large (80\%) and located on frontal (50\%) region. After the frontal region, the temporal and parietal regions were ranked second and third, respectively, in frequent surgical sites. Tumor was the most prevalent cause of surgery in this study (88\%). The relationships of craniotomy location with flap size and diseases are shown in Table 4. In most cases, large flaps were in frontal region. We considered flap size of $>16 \mathrm{~mm}^{2}$ as large. Chi-square was used to assess statistical significance of different variables. The calculated P-value proves the significance of these relationships (Table 5).

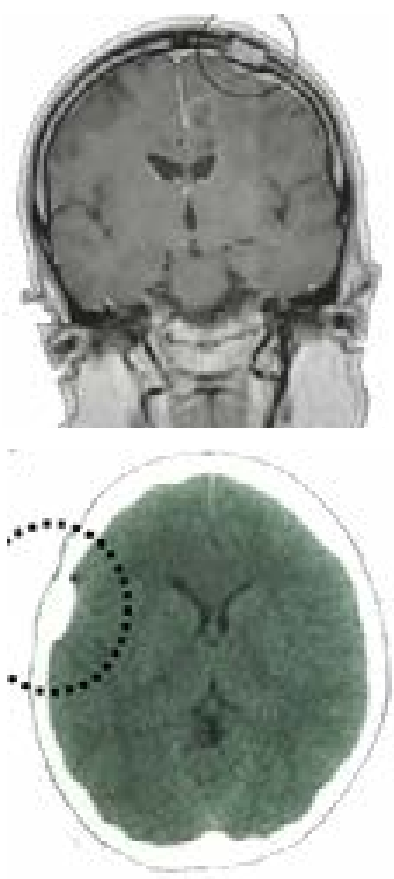

NS

Finally, the most important variables, the objectives of this study, are presented in Table 6. Totally, there was no evidence of loosening. Infection was reported only in one case (1.7\%). The cause of infection was investigated thorough product tracking form and the LOT number. Two Cranfixers were used for the infected case with same LOT number and sterilization date. The documentation and standard indicators show that both of these Cranfixers were sterilized in a standard manner, but only one of them was infected. As a result, based on these pieces of evidence, the probability that the infection had been caused by the product is very slight $(P<0.001)$. The responsible surgeon believed the silk stitch may have caused the infection.

Another important characteristic of Cranfixer is prominence after surgery. In five cases, the Cranfixer was touchable through scalp (8.3\%) and just three of them were visible if carefully inspected (5\%). This characteristic is not usually of clinical importance, but it may compromise patient's appearance and self-confidence. Therefore, it must be considered in future versions of Cranfixer.

\section{Discussion}

This study supports previous studies regarding biocompatibility of PMMA. Cranfixer revealed good performance regarding flap fixation and was easy to use 
Table 1. The datasheet of variables

\begin{tabular}{|c|c|c|c|c|c|c|c|c|c|c|c|c|}
\hline 운 & 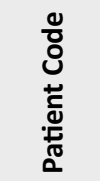 & $\begin{array}{l}\frac{\grave{d}}{0} \\
\frac{\mathrm{C}}{d}\end{array}$ & 峁 & 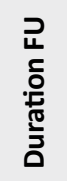 & $\dot{\mathbf{z}}$ & 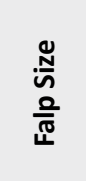 & 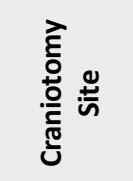 & 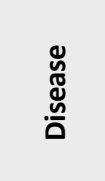 & 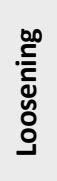 & 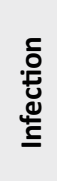 & 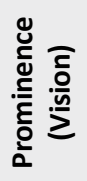 & 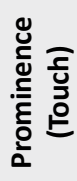 \\
\hline 1 & 8547 & Female & 48 & 219 & 2 & Small & Temporal & Tumor & No & No & No & No \\
\hline 2 & 16403 & Female & 56 & 143 & 1 & Small & Temporal & Tumor & No & No & No & No \\
\hline 3 & 22040 & Female & 52 & 188 & 2 & Large & Temporal & Tumor & No & No & No & No \\
\hline 4 & 24445 & Male & 45 & 182 & 1 & Small & Parietal & Tumor & No & No & No & No \\
\hline 5 & 25394 & Male & 33 & 343 & 2 & Large & Frontal & Tumor & No & No & No & Yes \\
\hline 6 & 25718 & Male & 30 & 381 & 2 & Large & Temporal & Seizure & No & No & No & No \\
\hline 7 & 25904 & Female & 31 & 375 & 2 & Large & Frontal & Tumor & No & No & No & No \\
\hline 8 & 26426 & Female & 36 & 371 & 2 & Large & Frontal & Tumor & No & No & No & No \\
\hline 9 & 26695 & Male & 71 & 501 & 2 & Large & Frontal & Tumor & No & No & No & No \\
\hline 10 & 26777 & Male & 60 & 269 & 2 & Large & Frontal & Tumor & No & No & Yes & Yes \\
\hline 11 & 26934 & Female & 37 & 465 & 2 & Large & Frontal & Tumor & No & No & Yes & Yes \\
\hline 12 & 26992 & Female & 14 & 525 & 2 & Small & Parietal & Seizure & No & No & No & No \\
\hline 13 & 27060 & Female & 49 & 315 & 2 & Large & Frontal & Tumor & No & No & Yes & Yes \\
\hline 14 & 27165 & Male & 66 & 523 & 2 & Large & Frontal & Tumor & No & No & No & Yes \\
\hline 15 & 27202 & Female & 26 & 518 & 2 & Large & Frontal & Tumor & No & No & No & No \\
\hline 16 & 27246 & Female & 46 & 444 & 2 & Large & Frontal & Tumor & No & No & No & No \\
\hline 17 & 27255 & Male & 48 & 493 & 2 & Large & Frontal & Tumor & No & No & No & No \\
\hline 18 & 27273 & Female & 33 & 480 & 2 & Small & Temporal & Tumor & No & No & No & No \\
\hline 19 & 27308 & Male & 64 & 479 & 2 & Large & Occipital & Tumor & No & No & No & No \\
\hline 20 & 27323 & Male & 51 & 516 & 2 & Large & Parietal & Tumor & No & No & No & No \\
\hline 21 & 27339 & Female & 81 & 456 & 2 & Large & Frontal & Tumor & No & No & No & No \\
\hline 22 & 27346 & Male & 33 & 448 & 2 & Large & Frontal & Tumor & No & No & No & No \\
\hline 23 & 27352 & Male & 46 & 451 & 2 & Small & Temporal & Seizure & No & No & No & No \\
\hline 24 & 27367 & Female & 32 & 471 & 2 & Large & Frontal & Tumor & No & No & No & No \\
\hline 25 & 27392 & Male & 36 & 467 & 2 & Large & Frontal & Tumor & No & No & No & No \\
\hline 26 & 27407 & Female & 50 & 453 & 2 & Large & Parietal & Tumor & No & No & No & No \\
\hline 27 & 27426 & Female & 35 & 430 & 2 & Large & Frontal & Tumor & No & No & No & No \\
\hline 28 & 27435 & Male & 82 & 447 & 2 & Large & Frontal & Tumor & No & No & No & No \\
\hline 29 & 27455 & Male & 64 & 441 & 2 & Large & Parietal & Tumor & No & No & No & No \\
\hline 30 & 27460 & Male & 37 & 439 & 2 & Large & Frontal & Tumor & No & No & No & No \\
\hline 31 & 27511 & Male & 15 & 425 & 2 & Large & Occipital & Tumor & No & No & No & No \\
\hline 32 & 27512 & Male & 22 & 427 & 2 & Small & Parietal & Tumor & No & Yes & No & No \\
\hline 33 & 27594 & Female & 29 & 378 & 2 & Large & Frontal & Tumor & No & No & No & No \\
\hline 34 & 27612 & Female & 56 & 360 & 2 & Large & Frontal & Tumor & No & No & No & No \\
\hline 35 & 27629 & Male & 35 & 365 & 2 & Large & Parietal & Tumor & No & No & No & No \\
\hline 36 & 27650 & Male & 33 & 368 & 2 & Small & Temporal & Tumor & No & No & No & No \\
\hline 37 & 27662 & Male & 64 & 353 & 2 & Large & Frontal & Tumor & No & No & No & No \\
\hline 38 & 27676 & Male & 54 & 397 & 2 & Large & Temporal & Tumor & No & No & No & No \\
\hline 39 & 27694 & Male & 41 & 346 & 2 & Large & Frontal & Tumor & No & No & No & No \\
\hline 40 & 27716 & Male & 19 & 266 & 2 & Small & Parietal & Seizure & No & No & No & No \\
\hline
\end{tabular}




\begin{tabular}{|c|c|c|c|c|c|c|c|c|c|c|c|c|}
\hline 울 & 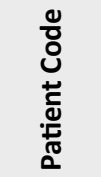 & 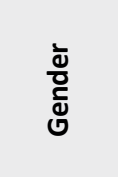 & 嵒 & 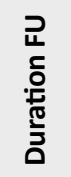 & ì & $\begin{array}{l}\stackrel{N}{n} \\
\text { 은 } \\
\text { 판 }\end{array}$ & 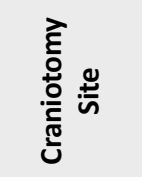 & 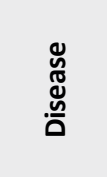 & 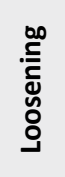 & 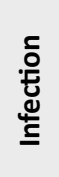 & 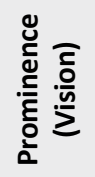 & 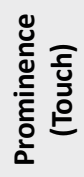 \\
\hline 41 & 27761 & Male & 58 & 322 & 2 & Large & Parietal & Tumor & No & No & No & No \\
\hline 42 & 27766 & Female & 53 & 327 & 2 & Large & Frontal & Tumor & No & No & No & No \\
\hline 43 & 27771 & Female & 38 & 307 & 2 & Small & Temporal & Seizure & No & No & No & No \\
\hline 44 & 27857 & Male & 68 & 302 & 2 & Large & Temporal & Tumor & No & No & No & No \\
\hline 45 & 27870 & Female & 52 & 288 & 2 & Large & Frontal & Tumor & No & No & No & No \\
\hline 46 & 27880 & Male & 38 & 301 & 2 & Large & Frontal & Tumor & No & No & No & No \\
\hline 47 & 27985 & Female & 17 & 168 & 2 & Small & Temporal & Seizure & No & No & No & No \\
\hline 48 & 28021 & Male & 21 & 274 & 2 & Large & Temporal & Tumor & No & No & No & No \\
\hline 49 & 28040 & Female & 50 & 171 & 2 & Large & Parietal & Tumor & No & No & No & No \\
\hline 50 & 28045 & Male & 15 & 215 & 2 & Small & Temporal & Seizure & No & No & No & No \\
\hline 51 & 28071 & Female & 45 & 235 & 2 & Large & Parietal & Tumor & No & No & No & No \\
\hline 52 & 28076 & Female & 55 & 230 & 2 & Large & Frontal & Tumor & No & No & No & No \\
\hline 53 & 28097 & Male & 57 & 222 & 2 & Large & Temporal & Tumor & No & No & No & No \\
\hline 54 & 28141 & Female & 25 & 194 & 2 & Large & Frontal & Tumor & No & No & No & No \\
\hline 55 & 28243 & Female & 69 & 211 & 2 & Large & Temporal & Tumor & No & No & No & No \\
\hline 56 & 28256 & Female & 59 & 208 & 2 & Large & Parietal & Tumor & No & No & No & No \\
\hline 57 & 28330 & Male & 40 & 165 & 2 & Large & Frontal & Tumor & No & No & No & No \\
\hline 58 & 28306 & Female & 62 & 157 & 2 & Large & Frontal & Tumor & No & No & No & No \\
\hline 59 & 28326 & Female & 30 & 154 & 2 & Large & Temporal & Tumor & No & No & No & No \\
\hline 60 & 28394 & Female & 37 & 161 & 2 & Large & Frontal & Tumor & No & No & No & No \\
\hline
\end{tabular}

Table 2. Age, follow-up duration, and number of Cranfixers per patient

\begin{tabular}{cccc}
\hline Variables & Min & Max & Mean \pm SD \\
\hline Age & 14 & 82 & $44.15 \pm 16.51$ \\
\hline Follow- up duration (day) & 143 & 525 & $342.17 \pm 117.49$ \\
Number of Cranfixers per patient & 1 & 2 & $1.98 \pm 1.81$ \\
\hline
\end{tabular}

Table 3. Some variables related to the surgery

\begin{tabular}{|c|c|c|c|}
\hline Variables & Type & Frequency & $(\%)$ \\
\hline \multirow{2}{*}{ Flap size } & Large & 48 & 80 \\
\hline & Small & 12 & 20 \\
\hline \multirow{4}{*}{ Craniotomy site } & Frontal & 30 & 50 \\
\hline & Occipital & 2 & 3 \\
\hline & Parietal & 12 & 20 \\
\hline & Temporal & 16 & 27 \\
\hline \multirow{2}{*}{ Disease } & Seizure & 7 & 12 \\
\hline & Tumor & 53 & 88 \\
\hline
\end{tabular}


Table 4. The frequency of flap size and disease in each craniotomy location

\begin{tabular}{|c|c|c|c|c|c|}
\hline \multicolumn{2}{|c|}{ Description } & \multirow{2}{*}{$\begin{array}{c}\text { Frontal } \\
30\end{array}$} & \multirow{2}{*}{$\begin{array}{c}\text { Occipital } \\
2\end{array}$} & \multirow{2}{*}{$\begin{array}{c}\text { Parietal } \\
8\end{array}$} & \multirow{2}{*}{$\begin{array}{c}\text { Temporal } \\
8\end{array}$} \\
\hline & Large & & & & \\
\hline & Small & 0 & 0 & 4 & 8 \\
\hline \multirow{2}{*}{ Disease } & Seizure & 0 & 0 & 2 & 5 \\
\hline & Tumor & 30 & 2 & 10 & 11 \\
\hline
\end{tabular}

5. The results of chi-square test

\begin{tabular}{|c|c|c|c|c|}
\hline \multicolumn{2}{|c|}{ Description } & \multirow{2}{*}{$\begin{array}{c}\text { value } \\
18.33\end{array}$} & \multirow{2}{*}{$\frac{\text { df }}{3}$} & \multirow{2}{*}{$\frac{\mathbf{P}}{0.000}$} \\
\hline & Pearson's chi-square & & & \\
\hline \multirow[t]{3}{*}{$\begin{array}{l}\text { Relationship between } \\
\text { flap size and craniotomy site }\end{array}$} & Likelihood ratio & 22.60 & 3 & 0.000 \\
\hline & Number of valid cases & 60 & - & - \\
\hline & Pearson chi-square & 10.47 & 3 & 0.015 \\
\hline \multirow[t]{2}{*}{$\begin{array}{l}\text { Relationship between } \\
\text { disease and craniotomy site }\end{array}$} & Likelihood ratio & 12.54 & 3 & 0.006 \\
\hline & Number of valid cases & 60 & & \\
\hline
\end{tabular}

Table 6. The clinical variables

\begin{tabular}{|c|c|c|c|}
\hline Variables & & Frequency & (\%) \\
\hline \multirow{3}{*}{ Loosening } & No. & 60 & 100 \\
\hline & Yes & 0 & 0 \\
\hline & Total & 60 & 100 \\
\hline \multirow{3}{*}{ Infection } & No. & 59 & 98.3 \\
\hline & Yes & 1 & 1.7 \\
\hline & Total & 60 & 100 \\
\hline \multirow{3}{*}{$\begin{array}{l}\text { Prominent } \\
\text { (visual) }\end{array}$} & No. & 57 & 95 \\
\hline & Yes & 3 & 5 \\
\hline & Total & 60 & 100 \\
\hline \multirow{3}{*}{ Prominent (tactile) } & No. & 55 & 91.7 \\
\hline & Yes & 5 & 8.3 \\
\hline & Total & 60 & 100 \\
\hline
\end{tabular}


according to the surgeon. Thickness of the device is a point for further revision and development.

Our clinical investigation lasted up to 18 months, and we observed the following characteristics of Cranfixer: 1. Good performance in the flap fixation; 2. Excellent biocompatibility; 3 . user-friendliness and ease to use from the surgeons' point of view. Furthermore, the thickness of Cranfixer should be revised without loss of strength and product performance.

\section{Ethical Considerations}

Compliance with ethical guidelines

The Case Report Form (CRF) and informed consent of this study were designed and used according to the approved procedure of Food and Drug Administration of Iran. The questionnaire and method of this study were evaluated and approved by the Research Deputy of Tehran University of Medical Sciences (IR.TUMS.VCR. REC.1397.657).

Funding

The financial support of the project was provided by Darman Afarin Noandish Afagh (DanaWell) company (IRCT20190528043740N1).

\section{Authors contributions}

Conceiving and designing the study: Seyed Roholah Ghodsi, Zahra Namazi; Data collection and manuscript drafting: Hosein Esmaili Dezaki, Zahra Faraji; Data collection and statistical analysis: Morteza Alizadeh, Hosein Esmaili Dezaki; Study design and analyses; Seyed Roholah Ghodsi, Zahra Namazi, Morteza Alizadeh

\section{Conflict of interest}

The authors with DanaWell affiliation have indirect financial interest in the subject matter discussed in this paper.
[2] Blair GA, Fannin TF, Gordon DS. Titanium-strip cranioplasty. British Medical Journal. 1976; 2(6041):907-8. [DOI:10.1136/ bmj.2.6041.907] [PMID] [PMCID]

[3] Estin D, Troffkin N, Heilman CB. Bone flap fixation with titanium clamps: A new technique. Surgical Neurology. 2000; 53(4):391-4. [DOI:10.1016/S0090-3019(00)00186-5] [PMID]

[4] Van Loock K, Menovsky T, Kamerling N, De Ridder D. Cranial bone flap fixation using a new device (Cranial LoopTM). Minimally Invasive Neurosurgery: MIN. 2011; 54(3):119-24. [DOI:10.1055/s-0031-1283171] [PMID]

[5] Thomson LA, Law FC, James KH, Matthew CA, Rushton N. Biocompatibility of particulate polymethylmethacrylate bone cements: A comparative study in vitro and in vivo. Biomaterials. 1992; 13(12):811-8. [DOI:10.1016/0142-9612(92)90173-L]

[6] Fiaschi P, Pavanello M, Imperato A, Dallolio V, Accogli A Capra V, et al. Surgical results of cranioplasty with a polymethylmethacrylate customized cranial implant in pediatric patients: A single-center experience. Journal of Neurosurgery: Pediatrics. 2016; 17(6):705-10. [DOI:10.3171/2015.10 PEDS15489] [PMID]

\section{References}

[1] Julian OC, Lopez-Belio M, Dye WS, Javid H, Grove WJ. The median sternal incision in intracardiac surgery with extracorporeal circulation; A general evaluation of its use in heart surgery. Surgery. 1957; 42(4):753-61. [PMID] 